\title{
Multifunctional T/RH-sensitive thick-film structures for environmental sensors
}

\author{
Klym Halyna ${ }^{1,2}$, Hadzaman Ivan ${ }^{2,3}$, Shpotyuk Oleh ${ }^{2,4}$, Brunner Michael ${ }^{5}$ \\ ${ }^{1}$ Lviv Polytechnic National University, \\ 12, Bandera str., 79013, Lviv, Ukraine \\ ${ }^{2}$ Lviv Scientific Research Institute of Materials of SRC "Carat", \\ 202, Stryjska str., 79031, Lviv, Ukraine \\ ${ }^{3}$ Drohobych Ivan Franko State Pedagogical University, \\ 24, I. Franko str., 82100, Drohobych, Ukraine \\ ${ }^{4}$ Institute of Physics of Jan Dlugosz University, \\ 13/15, Al. Armii Krajowej, 42201 Czestochowa, Poland \\ ${ }^{5}$ Fachhochschule Köln / University of Applied Sciences, \\ 2, Betzdorfer Strasse, 50679, Köln, Germany \\ Phone: +380978483867, e-mail: klymha@yahoo.com
}

\begin{abstract}
Multifunctional T/RT-sensitive thick-film structures based on spinel-type semiconducting and insulating ceramics of different chemical composition $\mathrm{Cu}_{0.1} \mathrm{Ni}_{0.1} \mathrm{Co}_{1.6} \mathrm{Mn}_{1.2} \mathrm{O}_{4}$ (with $\mathrm{p}^{+}$-type of electrical conductivity), $\mathrm{Cu}_{0.1} \mathrm{Ni}_{0.8} \mathrm{Co}_{0.2} \mathrm{Mn}_{1.9} \mathrm{O}_{4}$ (with $\mathrm{p}$-type of electrical conductivity) and magnesium aluminate $\mathrm{i}-$ type $\mathrm{MgAl}_{2} \mathrm{O}_{4}$ ceramics were fabricated and investigated. These sensor elements are shown to be successfully applied for integrated $\mathrm{T} / \mathrm{RH}$-sensitive environmental sensors.
\end{abstract}

Keywords: multilayer structure, sensor, spinel, thick-film, environment monitoring

\section{Introduction}

The simultaneous temperature $(T)$ and relative humidity $(\mathrm{RH})$ control consists in principally different sensitivities of monitored solid-state system to thermally- and moisture-activated environmentally-induced processes [1]. The basis functioning principle of T-measuring systems are grounded, as a rule, on some changes in their physical properties, such as electrical conductivity, resistance, capacity, optical absorption, magnetic susceptibility etc. stimulated by ambient temperature variations. Despite time delaying in system response on these variations caused by relative durability of temperature-influenced effects, the controlled parameter can be determined finally with a high accuracy. In contrast, the $\mathrm{RH}$ measurements are based on changes in physical properties of solid bulk or surface produced by absorbed water. The greater amount of absorbed water molecules, the better exploitation sensitivity of $\mathrm{RH}-$ measuring solid systems can be achieved.

To join both T- and RH-measuring working cycles, the combined resolution built on independent temperature determination for conventional $\mathrm{RH}$-sensitive functional element and, vice versa, - humidity determination for conventional temperature-sensitive element, - was proposed. The first approach was typically applied to perovsite-type thick films like to $\mathrm{BaTiO}_{3}$ [2]. Only one work represented the second approach and performed in Engineering Research Centre for Functional Ceramics of Huazhang University of Science and Technology (China) [3] should be mentioned as the most essential scientific achievements in the field of integrated temperature and humidity-sensitive sensors.

The use of spinel-based $\mathrm{NiMn}_{2} \mathrm{O}_{4}-\mathrm{CuMn}_{2} \mathrm{O}_{4}-\mathrm{MnCo}_{2} \mathrm{O}_{4}$ manganites with negative temperature coefficient (NTC) resistance for fabrication of disc-type NTC thermistors and humidity-sensitive $\mathrm{MgAl}_{2} \mathrm{O}_{4}$ by means of conventional ceramic technology was shown by us earlier [4-6]. However, applications in modern microelectronics (temperature and humidity sensors, fire detectors, power-sensing terminations, temperature-compensating attenuators, etc. [7]) require obtaining these materials in thick-film performance.

The well-known advantages of screen-printing technology revealed in high reproducibility, flexibility, attainment of high reliability by glass coating as well as excellent accuracy, yield and interchangeability by functional trimming are expected to be very attractive now, for new-generation sensing electronics [7]. No less important is the factor of miniaturization for developed thick-film elements and systems, realized in a variety of their possible geometrical configurations. Thus, the development of high-reliable nanostructured thick films and their multilayers based on spinel-type compounds for environmental sensors operating as integrated T-RH sensors are very important task [8-10].

Thick-film performance of mixed spinel-type manganites restricted by $\mathrm{NiMn}_{2} \mathrm{O}_{4}-\mathrm{CuMn}_{2} \mathrm{O}_{4}-\mathrm{MnCO}_{2} \mathrm{O}_{4}$ concentration triangle has a number of essential advantages, non-available for other ceramic composites. Within the above system, the fine-grained semiconductor materials possessing $p^{+}$-type 
$\mathrm{Cu}_{0.1} \mathrm{Ni}_{0.1} \mathrm{Mn}_{1.2} \mathrm{Co}_{1.6} \mathrm{O}_{4}$ and $\mathrm{p}$-type $\mathrm{Cu}_{0.1} \mathrm{Ni}_{0.8} \mathrm{Mn}_{1.9} \mathrm{Co}_{0.2} \mathrm{O}_{4}$ conductivity can be easily prepared. So, a real possibility to prepare integrated multilayer thick-film spinel-type structures for principally new device application. In addition, the prepared multilayer thick-film structures involving semiconductor $\mathrm{NiMn}_{2} \mathrm{O}_{4}{ }^{-}$ CuMn $\mathrm{O}_{4}-\mathrm{MnCo}_{2} \mathrm{O}_{4}$ and insulating i-type $\mathrm{MgAl}_{2} \mathrm{O}_{4}$ spinels can be used as integrated $\mathrm{T} / \mathrm{RH}$ environmental sensors with rich range of exploitation properties.

The aim of this work is development of $\mathrm{T} / \mathrm{RH}$-sensitive thick-film structures for ecological environment control and monitoring.

\section{Experimental}

Bulk thermistor ceramics were prepared by a conventional ceramic processing route using reagent grade copper carbonate hydroxide and nickel (cobalt, manganese) carbonate hydroxide hydrates. [11]. $\mathrm{Cu}_{0.1} \mathrm{Ni}_{0.1} \mathrm{Co}_{1.6} \mathrm{Mn}_{1.2} \mathrm{O}_{4}$ ceramics were sintered at temperature $1040{ }^{\circ} \mathrm{C}$ during 4 hours, $\mathrm{Cu}_{0.1} \mathrm{Ni}_{0.8} \mathrm{Co}_{0.2} \mathrm{Mn}_{1.9} \mathrm{O}_{4}$ ceramics were sintered at $920{ }^{\circ} \mathrm{C}$ during 8 hours, then 1 hour at $1200{ }^{\circ} \mathrm{C}$ and 920 ${ }^{\circ} \mathrm{C}$ during 24 hours.

Bulk $\mathrm{MgAl}_{2} \mathrm{O}_{4}$ ceramics were prepared via conventional sintering route as was described in more details elsewhere $[6,12]$. The pellets were sintered in a special regime with maximal sintering temperature of $1300^{\circ} \mathrm{C}$ during $5 \mathrm{~h}$.

Temperature sensitive $\mathrm{Cu}_{0.1} \mathrm{Ni}_{0.1} \mathrm{Co}_{1.6} \mathrm{Mn}_{1.2} \mathrm{O}_{4} / \mathrm{Cu}_{0.1} \mathrm{Ni}_{0.8} \mathrm{Co}_{0.2} \mathrm{Mn}_{1.9} \mathrm{O}_{4}$-based pastes were prepared by mixing powders of basic ceramics (sintered bulk ceramic discs were preliminary crushed, wet-milled in isopropyl alcohol medium and dried) with ecological glass powder, $\mathrm{Bi}_{2} \mathrm{O}_{3}$ (inorganic binder) and an organic vehicle (contained organic binder and organic solvent). Thus, the two thermistor pastes and one dielectric paste on the basis of the spinel-type ceramics were obtained (Table 1).

Table 1

Composition of $\mathrm{T} / \mathrm{RH}$ sensitive pastes

\begin{tabular}{|c|c|c|c|c|}
\hline \multirow{2}{*}{ Based paste } & \multicolumn{4}{|c|}{ Paste constituents, \% mass } \\
\cline { 2 - 5 } & Basic ceramics & $\mathrm{Bi}_{2} \mathrm{O}_{3}$ & Ecological glass & Organic vehicle \\
\hline $\begin{array}{c}\mathrm{Cu}_{0,1} \mathrm{Ni}_{0,1} \mathrm{Co}_{1,6} \mathrm{Mn}_{1,2} \mathrm{O}_{4} / \\
\mathrm{Cu}_{0,1} \mathrm{Ni}_{0,8} \mathrm{Co}_{0,2} \mathrm{Mn}_{1,9} \mathrm{O}_{4}\end{array}$ & 72.8 & 2.9 & 2.9 & 21.4 \\
\hline $\mathrm{MgAl}_{2} \mathrm{O}_{4}$ & 58 & 4 & 8 & 30 \\
\hline
\end{tabular}

The prepared pastes were printed on alumina substrates (Rubalit 708S) with Ag electrodes using a manual screen-printing device equipped with a steel screen. Then thick films were fired in furnace PEO$601-084$ at $850{ }^{\circ} \mathrm{C}$ (the temperature-time firing schedule was similar to that, applied for the metallization of dick-type thermistors).

The insulating (i-type) paste was printed on alumina substrates with $\mathrm{Ag}$ electrodes and previous formed temperature-sensitive ( $p$-type) thick-film layer. From above of thick film, the $\mathrm{p}^{+}$-conductive paste electrodes were formed for study of electrophysical properties of humidity-sensitive thick-film elements. Then these structures were fired in furnace.

For investigation we used one-layered p-conductive $\mathrm{Cu}_{0.1} \mathrm{Ni}_{0.8} \mathrm{Co}_{0.2} \mathrm{Mn}_{1.9} \mathrm{O}_{4}, \mathrm{p}^{+}$-conductive $\mathrm{Cu}_{0.1} \mathrm{Ni}_{0.1} \mathrm{Co}_{1.6} \mathrm{Mn}_{1.2} \mathrm{O}_{4}$ thick films, double-layered $\mathrm{p}$ - $\mathrm{p}^{+}$thick-film structure, i-type $\mathrm{MgAl}_{2} \mathrm{O}_{4}$ thick-film formed on substrate with Ag-electrical contacts and integrated $\mathrm{T} / \mathrm{RH}$-sensitive thick-film sensor structure (last see in the topological scheme on Fig. 1).

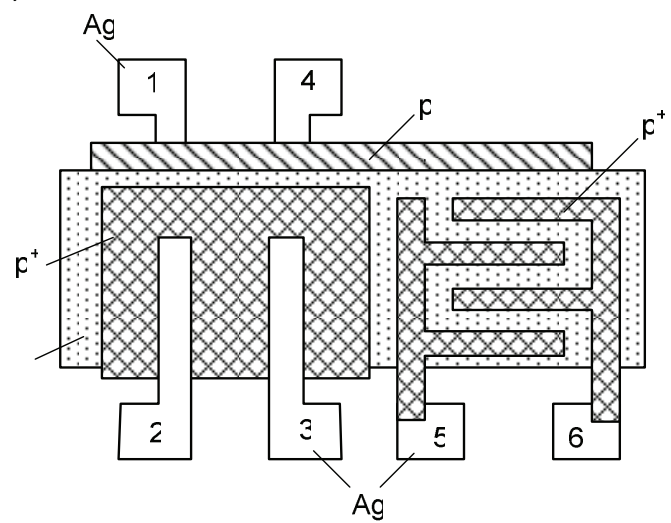

Fig. 1. Topological scheme of $\mathrm{T} / \mathrm{RH}$-sensitive thick-film structures 
The topology of the obtained thick films was investigated using 3D-profilograph Rodenstock RM600. The electrical resistances of T-sensitive thick films were measured with precise digital multimeters using temperature chambers MINI SABZERO, model MC-71 and HPS 222. The temperature constant $B$ for these thick films was calculated according to the equation:

$$
B=2.3026 \cdot \log \left(\frac{R_{1}}{R_{2}}\right) \cdot \frac{T_{1} \cdot T_{2}}{T_{2}-T_{1}},
$$

where $R_{1}$ and $R_{2}$ were corresponding resistance at $T_{1}=25^{\circ} \mathrm{C}$ and $T_{2}=85^{\circ} \mathrm{C}$. accordingly.

The $\mathrm{RH}$-sensitivity thick films based on $\mathrm{MgAl}_{2} \mathrm{O}_{4}$ ceramics is determined by dependence of electrical resistance $\mathrm{R}$ on $\mathrm{RH}$ of environment.

The electrical resistance of the studied samples was measured in the heat and moisture chamber PR-3E "TABAl" at temperatures 20 and $50{ }^{\circ} \mathrm{C}$ on the region of $\mathrm{RH}=25-99 \%$. The values of necessary temperature and humidity were set by two temperature sensors placed on the front panel of this chamber. Transition in the mode of humidity was carried out by the special switch (placed on the forehand of panel). After that, the refrigerator was included for providing of stability. Regulation and stabilization of humidity in the chamber was carried out by the values of humidity. Additionally, the two digital thermometers of TO-ЦО24 (area of measuring of temperatures: $-80 \div 250{ }^{\circ} \mathrm{C}$ ) were assembled in a chamber for large exactness of experimental results.

The studied thick-film samples were fastened on the special clamps and placed on a chamber. The electrodes were given on the connecting cables of M-ohmmeter of alternating current of МОL-0104 at the fixed frequency of current of $500 \mathrm{~Hz}$. The areas of measuring of electric resistance were 0.001-1.999 MOhm; 2.00-19.99 MOhm; 20.0-199.9 MOhm and 200-1000 MOhm. The testing was carried out tested by cycles in direction of increase of $\mathrm{RH}$ and in reverse direction.

The value of $\mathrm{RH}$ for studied thick-film samples was determined on the result of the wet thermometer using psychrometric tables. As results, the values of electrical resistance $R$ as function of $\mathrm{RH}$ at temperatures $20^{\circ} \mathrm{C}$ and frequencies of signal $500 \mathrm{~Hz}$ were obtained.

\section{Result and discussion}

According to obtained 3D-profilogramph data, the thickness of temperature sensitive $\mathrm{p}^{+}$-conductive thick films based on $\mathrm{Cu}_{0.1} \mathrm{Ni}_{0.1} \mathrm{Co}_{1.6} \mathrm{Mn}_{1.2} \mathrm{O}_{4}$ ceramics and p-conductive thick films based on $\mathrm{Cu}_{0.1} \mathrm{Ni}_{0.8} \mathrm{Co}_{0.2} \mathrm{Mn}_{1.9} \mathrm{O}_{4}$ ceramics were near 47-49 $\mu \mathrm{m}$ and 54-63 $\mu \mathrm{m}$, accordingly. The thickness of multilayered $\mathrm{p}^{+}$-d thick-film structures was near $135.94 \mu \mathrm{m}$.

The T-sensitive $p^{+}$- and $p$-conductive thick films and their $p^{+}-p$ structures based on spinel-type $\mathrm{NiMn} \mathrm{O}_{4}-\mathrm{CuMn}_{2} \mathrm{O}_{4}-\mathrm{MnCo}_{2} \mathrm{O}_{4}$ ceramics posses good linear electrophysical characteristics in the region from 298 to $358 \mathrm{~K}$ in semi-logarithmic scale (Fig. 2). The values of $\mathrm{B}$ constants were 3589,3630 and $3615 \mathrm{~K}$ for $\mathrm{p}-, \mathrm{p}^{+}$-conductive thick films and $\mathrm{p}^{+}-\mathrm{p}$ structure, respectively.

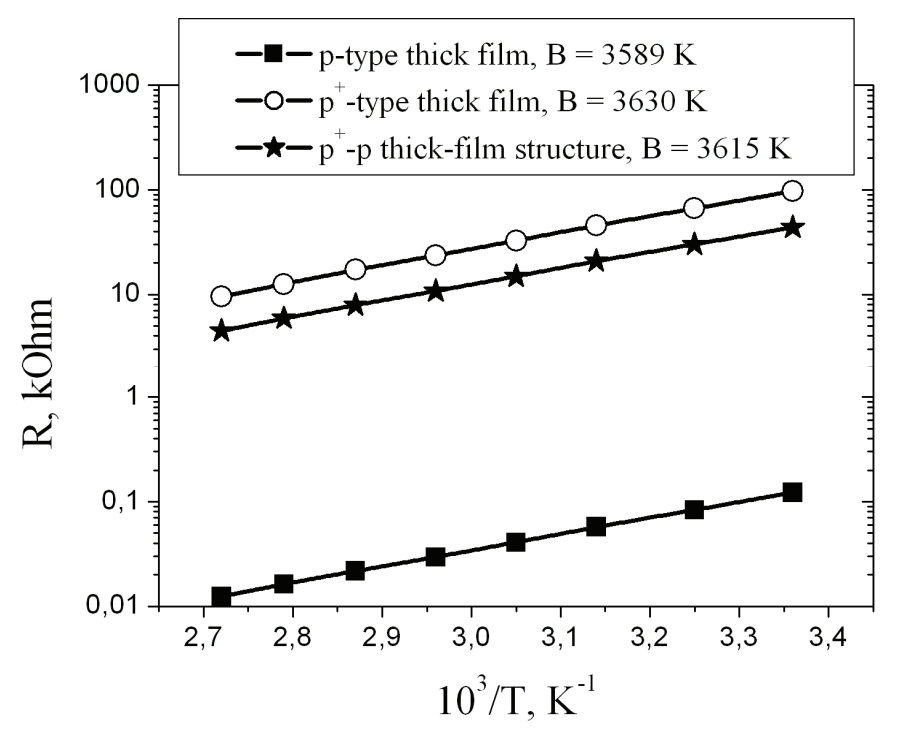

Fig 2. R/T characteristics for $\mathrm{p}$ - and $\mathrm{p}^{+}$-conductivity thick films

Firstly, in i-type RH-sensitive thick-film elements we used the Ru-contained paste electrodes from above thick film for study their electrophysical properties. After initial electrophysical investigation these 
humidity-sensitive thick-film elements based on $\mathrm{MgAl}_{2} \mathrm{O}_{4}$ ceramics posses good linear dependence of electrical resistance from relative humidity without hysteresis in the range of relative-humidity of $40-99 \%$. But after natural physical storage during 2-3 months, the elements lose of RH-sensitivity (see Fig. 3).

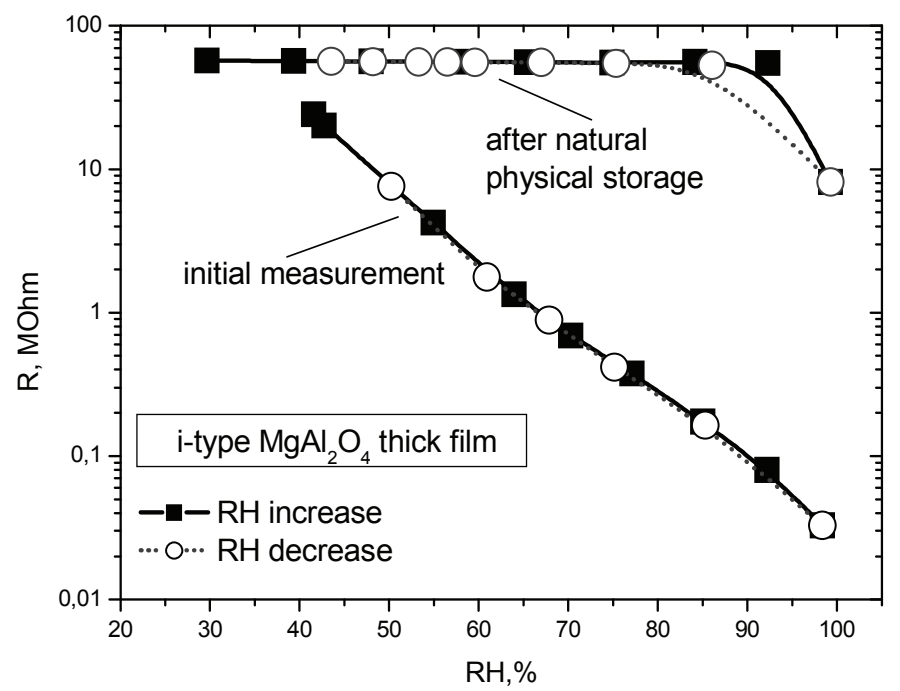

Fig. 3. $\mathrm{RH}$ characteristics for initial i-type thick film and after natural physical storage

It is established [13], that this effect caused by degradation processes in Ag-Ru contacts area. Sensitivity of i-type thick film succeeds to be picked up thread after the repeated update of contact. But this sensitivity can be again lost after some time.

So, with the aim of avoid of this problem, the p+-conductive paste was used as the new contact area formed on i-type $\mathrm{MgAl}_{2} \mathrm{O}_{4}$ thick film layer. Since all components ( $\mathrm{p}-, \mathrm{p}^{+}-$and d-type thick films) are of the same chemical type (spinel-like) and possess high T/RH sensitivities, they will be positively distinguished not only by wider functionality (simultaneous $\mathrm{T} / \mathrm{RH}$ sensing), but also unique functional stability. In addition, we obtained integration $\mathrm{T} / \mathrm{RH}$ sensor structures in the new geometrical design and with the large $\mathrm{RH}$-sensitive active area (see Fig. 1, right part, 5 and 6 electrodes).

The dependences of electrical resistance $\mathrm{R}$ from $\mathrm{RH}$ for integrated $\mathrm{p}$-i-p ${ }^{+}$structures in new design was shown in Fig. 4. In the results of electrophysical measurements, it was established that such thickfilm structures posses humidity-sensitivity within one-order change of electrical resistance.

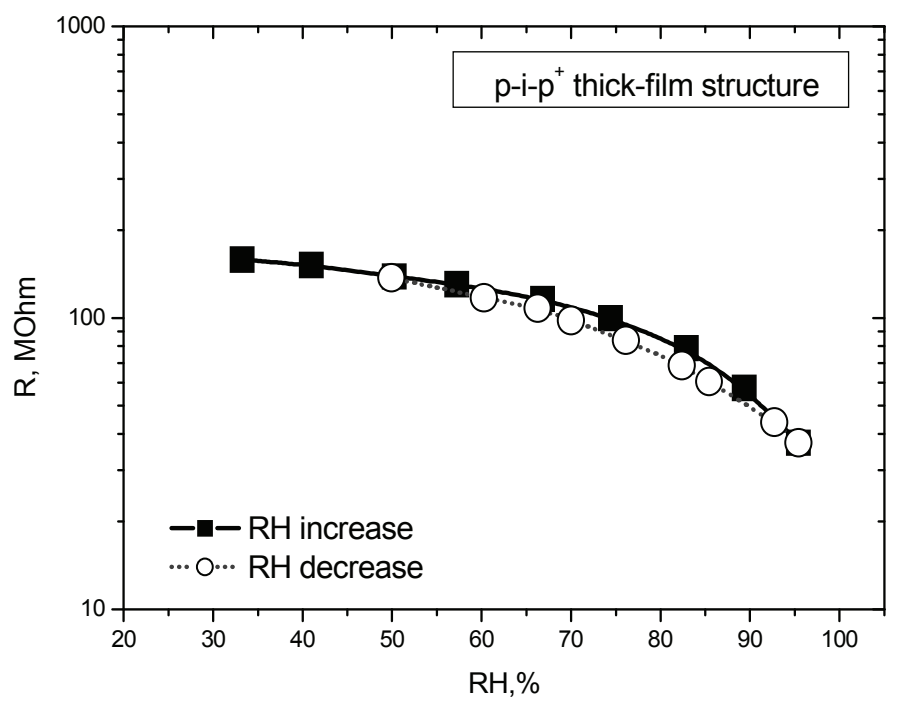

Fig. 4. RH characteristics for integrated $p-i-p^{+}$structure 
These changes can be connected with diffusion processes of the elements from $p$ - and $p^{+}-$ conductive T-sensitive thick-film layers on i-type $\mathrm{RH}$-sensitive thick-film. In the results, some active pores will not take part in adsorption-desorption processes. So, this effect needs a future investigation.

\section{Conclusion}

In the results of electrophysical measurements, it was shown that just prepared RH-sensitive thick films posses good linear dependence of electrical resistance from $\mathrm{RH}$ without hysteresis in the range of $\mathrm{RH}$ of $40-99 \%$. After reiterated electrophysical measurements of theses thick-film sensor elements saved at the normal physical condition was lose of their sensitivity. This effect connected with degradation on contact area. The new integrated spinel-type T/RH sensitive $p$-i- $p^{+}$thick-film structures shown $\mathrm{RH}-$ sensitivity within one-order change of electrical resistance.

So, separate $\mathrm{T}$ - and $\mathrm{RH}$-sensitive thick-film elements based on spinel-type $\mathrm{NiMn}_{2} \mathrm{O}_{4}-\mathrm{CuMn}_{2} \mathrm{O}_{4}-$ $\mathrm{MnCo}_{2} \mathrm{O}_{4}$ manganites, their $\mathrm{p}^{+}$-p structures and i-type $\mathrm{MgAl}_{2} \mathrm{O}_{4}$ can be used to produce multilayered $\mathrm{T} / \mathrm{RH}$-sensitive thick-film sensor structures for ecological environment monitoring and control.

\section{References}

1. A.P.H. Goede, and J.P. Burrows, "Energy and Environment", The intimate link, 2009, vol. 40(4), pp. 4-6.

2. J. Holc, "Temperature characteristics of electrical properties of $(\mathrm{Ba}, \mathrm{Sr}) \mathrm{TiO}_{3}$ thick-film humidity sensors", Sensors and Actuators, 1995, vol. B 26/27, pp. 99-102.

3. J. Huang, "Preparation and characteristic of the thermistor materials in the thick-film integrated temperature-humidity sensor", Material Science and Engineering, 2003, vol. B99, pp. 523-526.

4. M. Vakiv, O. Shpotyuk, O. Mrooz, and I. Hadzaman, "Controlled thermistor effect in the system $\mathrm{Cu}_{x} \mathrm{Ni}_{1-x-y} \mathrm{Co}_{2 y} \mathrm{Mn}_{2-y} \mathrm{O}_{4}$ ", Journal of the European Ceramic Society, 2001, vol. 21, pp. 1783-1785.

5. M.M. Vakiv, I.V. Hadzaman, A.P. Kovalskiy, M.M. Kravtsiv, O.Ya. Mrooz, and O.I. Shpotyuk, Patent of Ukraine No 47534, H01C7/04, H01C7/13, C04B35/00 // C04B101:00, Prior.: 06.04.2000.

6. O. Shpotyuk, A. Ingram, H. Klym, M. Vakiv, I. Hadzaman, and J. Filipecki, "PAL spectroscopy in application to humidity-sensitive $\mathrm{MgAl}_{2} \mathrm{O}_{4}$ ceramics", Journal of the European Ceramic Society, 2005, vol. 25, pp. 2981-2984.

7. A.H. Feingold, R. L. Wahlers, P. Amstutz, C. Huang, S.J. Stein, and J. Mazzochette, "New microwave applications for thick-film thermistors", Microwave Journal, 2000, vol. 1, pp. 90-98.

8. W. Qu, "Development of multi-functional sensors in thick-film and thin-film technology", Measuring Science and Technology, 2000, vol. 11, pp. 1111-1115.

9. N.W. White, and J.D. Turner, "Thick-film sensors: past, present and future", Measuring Science and Technology, 1997, vol. 8, pp 1-4.

10. A. Dziedzic, "Thick-film resistive temperature sensors" Measuring Science and Technology, 1997, vol. 8, pp. 78-81.

11. I.B. Vynnyk, I.V. Hadzaman, H.I. Klym, O.Ya. Mrooz, and O.I. Shpotyuk, "Obtaining of magnesium aluminate ceramics with the improved humidity sensitivity characteristics", Technology Design in Electronics, 2006, vol. 2, pp. 60-62.

12. H. Klym, A. Ingram, O. Shpotyuk, J. Filipecki, and I. Hadzaman, "Extended positron-trapping defects in insulating $\mathrm{MgAl}_{2} \mathrm{O}_{4}$ spinel-type ceramics", Physica status solidi (c), 2007, vol. 4, No 3, pp. 715-718.

13. I. Hadzaman, H. Klym, O. Shpotyuk, M. Vakiv, "Degradation processes on the contact area in humidity-sensitive thick films", Abst. 4-th International Scientific and Technical Conference "Sensors Electronics and Microsystems Technology", Odessa, Ukraine, June 28 - July 2 2010, p. 317. 